\title{
Coordinating Development in Conflict States: Donor Networks in Somalia
}

\author{
Anna Schmidt
}

Abstract Aid coordination is part of the governance of public policy, affecting the accountability and effectiveness of aid as well as power relationships. Using the case of Somalia, this article analyses the coordination of aid in conflict settings. Somalia is marked by multidimensional involvement, 'remote control' from Nairobi, and a general unease about impact and accountability across all involved (donors, UN and Somali actors). 'Comprehensive' aid strategies that straddle various logics of engagement need to be given shape in situ, i.e. by relatively autonomous donor country offices. Here networks of relationships and coordination mechanisms shape decision-making and problem-framing. Often the size of one's development budget provides limited leverage. Despite much distrust, UN agencies provide a gatekeeper function vis-à-vis Somalia counterparts. Trilateral dialogue about aid remains largely symbolic and at the diplomatic level. While effective solutions to problems can be found, a lack of joint engagement based on publicly traceable 'technical' principles undermines both accountability and joint learning over time, in turn impacting trust.

\section{Introduction}

Multilevel, networked systems of governance are a fundamental fact of life in most African conflict settings. This necessitates an analytical focus on relationship dynamics across levels of governance, both formal and informal, and their role in conflict governance. Using this basic conceptual lens, this article looks at the coordination networks that influence the management of aid-in-conflict in the case of Somalia.

Not only is Somalia seen as the poster child of a 'failed state', the related aid efforts are frequently described as either misguided or unsuccessful. Be it the 15+ unsuccessful and internationally brokered and supported peace conferences and 'deals' (Menkhaus 2010, 2007), the large sums spent on aid in its various forms without any large impact (Norris and Bruton 2011), or the accusation of a self-interested 'aidindustry' managing support to Somalia through Nairobi-based 'remote control' (or 'remote management'), the Somalia donor community is not getting much positive press. To many, a large problem is that of coordination, which, if only improved, would increase both effectiveness and accountability of aid (OECD 2011: 14).
This article analyses the process of country-level aid coordination, situated between the broad allocation decisions at donor-capital level and the domestic preference formation at the recipient state government. At this intermediate level donor policies, be they project identification, programme allocations or monitoring mechanisms, are shaped by a recursive engagement with other donors, implementing partners and actors of the 'counterpart' or 'recipient country'.

Whether weak or strong, executed through informal channels, formal groupings or reliant on multilateral organisations, aid coordination is part of the governance of public policy affecting the accountability and effectiveness of aid as well as power relationships of the actors involved. Coordination at the country-level plays a role everywhere, but is of particular interest in fragile state contexts - and particularly so in the Somali case. This is due to the specific policy dilemmas of fragile states (and some specific to conflict situations) and the associated operating procedures on the donor side. More starkly than in more 'settled' aid contexts, various, simultaneous but often competing goals security, economic development, 'state-building'

IDS Bulletin Volume 44 Number 1 January 2013 C 2013 The Author. IDS Bulletin (C) 2013 Institute of Development Studies Published by Blackwell Publishing Ltd, 9600 Garsington Road, Oxford OX4 2DQ, UK and 350 Main Street, Malden, MA 02148, USA 
and 'peace-building' - as well as various strategic or political interests combine with difficult implementation contexts: a greater ability to act outside government counterparts' frameworks but also frequently less presence on the ground and greater operational risks overall. The results are conditions of extreme policy fluidity, where action at the intermediate, 'brokerage' level can shape both context and content of aid flows disproportionately. Here 'in-country' donor representatives take decisions on allocation, select and scope new projects or programmes, and have the ability to filter relevant information upwards, including about performance and other actors' behaviour. In such a context, beyond the lens of international aid systems or foreign policy analysis, donor engagement is more fully understood when analysed with regard to the dense web of relationship that is created, through continuous interaction, between UN actors, donor representatives and various Somali actors. All of these are connected - sometimes loosely, sometimes tightly - via a set of material ties (aid flows); formal contractual relationships; through information exchange; or, at the individual level, through personal affinities or animosities.

In this article, I first situate the approach used by reference to the general literature on the determinants of aid, the role of multilateral institutions and network relations. I then present the case of Somalia and its aid context, marked by multidimensional involvement, 'remote control' from Nairobi and a general unease about impact and accountability on all sides. The third section outlines how the specific problems of 'fragility' here impact on the usual metropolitancentric mechanisms for setting donor's development policies. 'Comprehensive' strategies that straddle various logics of engagement need to be given concrete shape in situ, i.e. by relatively autonomous donor country offices. The fourth section explores the experience in Somalia with the various 'in-use' networks of relationships and coordination mechanisms which shape actual decision-making and problem-framing on the ground - host-country leadership, multilateral organisations, formal committees and informal networks. The conclusion suggests answers to a number of related questions: What expectations do donors have for Somalia aid coordination, and, given these expectations, what factors enhance the ability of some donors to pursue their strategies successfully, i.e. what type of relational properties matter under what type of circumstances? Does coordination help define what actors want and whether they can get it? What can be learned about multilateral approaches to coordination?

Methodologically this article is based on practical experience as a governance and security adviser for the European Union Somalia Operations Unit, as well as a basic semistructured network survey with 12 members of the Somalia Donor Group (SDG) conducted in July 2012. ${ }^{1}$ A number of caveats apply: the analysis concentrates on the behaviour of traditional donors and the UN system, who are the participants in formal coordination bodies in Nairobi. I touch on, but do not discuss in detail, specific dynamics linked to military (nonDevelopment Assistance Committee) assistance or the humanitarian sector proper, distinct from development aid by purpose (the alleviation of immediate suffering rather than long-term change in socioeconomic circumstances), guided by the humanitarian principles of impartiality and needs-based assistance and defined by separate funding arrangements and mechanisms (see Macrae and ODI 2002; Hammond and Vaughan-Lee 2012). ${ }^{2}$ Most of the practical examples are from the 'governance' support sector. Moreover, while donor coordination and donor-recipient coordination in principle overlap, this article focuses on the former. This is partially a function of the specific Somalia context of 'remote management' and the absence of unitary state structures.

\section{Donor coordination and multilateralism in conflict states}

Aid analysis often concentrates on the relationship between the variously derived interests of donors and those of the recipient country and how this encounter in turn drives aid levels. Beyond this basic relationship, institutions of coordination and joint principles (multilateralism) may play various roles by shaping actor interests, facilitating dialogue on information flows and providing various degrees of 'rules of the game'. In the first perspective, 'coordination' is minimal and assumes the role of information-sharing only. The second lens focuses on stronger forms of coordinated or even organised joint action or structures. This article moves from either approach to an analysis of aid 
coordination in-country, seeing it as conditioned by relational networks and understanding this as a process of governance.

\subsection{Determinants of aid}

Most studies of the determinants of aid measure aid broadly in quantitative terms and try to account for the factors that drive geographical and quantitative allocations. Alesina and Dollar (2000) explain most cross-country differences in aid receipts by political and strategic factors, albeit with important national variations.

Many overviews identify a number of factors influencing historical trends in aid, including need (altruism); political ideology; the dominant development paradigm; the geopolitical position and economic interests of both donors and recipients, as well as bureaucratic influences or the day-to-day procedures of those in the aid business. While proxy measures for the first set of factors can often be found, the latter element is more difficult to study and thus much aid analysis can remain quite abstract, saying little about process-level outcomes and their influence on the quality of aid (Hjertholm and White 2000; Tarp 2000).

One visible part of such decision-making processes is arguably the ever more complex international aid architecture. Possibly due to the multiplicity of actors and their often complicated and often conflicting interests, coordination and the establishment of norms and rules to guide engagement have been a clear trend in aid relationships. Today a host of multilateral arrangements are used to facilitate aid management, including the system of international organisations coordinating or channelling aid flows such as the United Nations Development Programme (UNDP), the Organisation for Economic Co-operation and Development (OECD), the international development banks, and also the system of aid summits and pledging conferences or informal 'friends of' groups.

\subsection{Coordination regimes and multilateralism}

For some donors multilateral agencies may simply be an implementing partner, yet the principle of multilateralism itself carries heavier baggage. Ruggie famously defines it as an 'institutional form that co-ordinates relations among three or more states on the basis of generalised principles of conduct', i.e. without regard to the particularistic or strategic interests of the parties in any specific settings (1993: 11). As such, 'multilateralism' includes a belief that certain activities ought to be organised on a universal basis at least for a relevant group. This differentiates it from power politics and strategic alliances. In network language, institutional and normative ties are created or strengthened to soften the role of pure egocentric interest.

Multilateralism is often seen as 'stronger' when embodied in formal institutions and independent organisations which have the specific purpose of upholding the principles of a multilateral agreement or norm. As such the Organisation for Economic Co-operation and Development/ Development Assistance Committee (OECD/DAC) tables distinguish between bilateral and multilateral aid by reference to the institutional form through which money is channelled.

The theoretical literature tends either to hold that for 'what really matters' interest cannot be diffused, or to emphasise a variety of positive effects of institutionalised multilateralism. The latter points out the upholding of professional legal or moral norms, the idea that institutions can constrain behaviour, influence preferences, reduce the cost and time of negotiation, provide information, and stabilise expectations about the behaviour of others and in short serve as a guide to 'right' action, diffusing interest of foreign policy and promoting learning and debate in the common interest. Here a famous statement was the UN-commissioned Pearson report in 1969 which summarised:

The aid dialogue involves sensitive questions of performance monitoring and advice and persuasion in matters of policy and planning. By playing a leading role as intermediaries in this ongoing debate between the suppliers and users of aid, international organisations do much to endow development assistance with the character of a truly international effort, reducing any overtones of charity or interventionism which have at times embittered the aid process in the past (World Bank 1969: 213-4).

Of course since then the role of these intermediaries themselves has been criticised as 
much as that of the initially primary actors, proving - among other things - that overtones of charity and problematic relationships are not the purview of one type of actor.

Aid coordination can result in multilateralism but is generally based on softer forms of organising than incorporation within international institutions. The OECD method is a mix in this respect, based on building up international networks around processes of common standardsetting. The dynamics can overlap with those uncovered by studies of the role of transnational networks in various issue-areas, where harmonisation of policy across different governments through specialised units (security regulators, central bankers, professional networks, etc.) create direct links between substate officials without close supervision (Grant and Keohane 2005; Slaughter 2004).

In practice, and especially in a fragile state context, multiple actors with multiple priorities encounter each other with conflicting objectives and little clear formal frameworks to go by, be it in terms of guidelines for actions or ultimate decision-making authority. They operate (1) with vague policy prescriptions, (2) relative autonomy and (3), in the Somali case in particular, without a mutually recognised coordinator. In any fragile state context, the model of traditional recipient country coordination or straightforward bilateral negotiation is undermined by the relative weakness of the recipient country government structures. In Somalia, the single government counterpart is replaced by a number of regional authorities and a nominally but not effectively sovereign central government that executes little of the functions associated with governing. Donors engage with their de facto interlocutors in differentiated ways. At the same time, for reasons outlined below, the relative lack of strong government leadership is not filled by multilateral organisations, which frequently play only a limited role in coordination. In this context a network perspective can help look at how decisions are made (or not) and what influences various actors in their decision-making. The term 'networks' is here understood in part as relating to networks-asactors, i.e. networks as an organisational form, but is primarily used as a conceptual tool that emphasises relationships or networks as proximate structures, i.e. patterns of relations that condition action (see Schmidt 2006; Elkins 2009: 44).

\section{Somalia, the poster child of the fragile state} problem

Much debate surrounds the concept of state 'fragility', yet in the case of Somalia, the debate around the precise meaning, function and utility of the associated measures can seem secondary. Whatever measure is used, the country seems to come out on top. Somalia leads all but one of the major fragile state indices available, as well as adjacent ones, such as Transparency International's corruption index. ${ }^{3}$ This may seem somewhat unfair given the vibrancy of (parts of) its private sector and the relative political stability achieved in the north, notably by Somaliland (Harper 2012). Yet as a whole, the country remains the most longstanding example of state collapse, containing no functioning national government but instead various political entities with competing claims for territory and authority. The two regional authorities of Somaliland and Puntland have, however, been able to restore different degrees of stability. Somaliland's 2010 presidential elections ushered in a peaceful transfer of power, unique in the region. Yet both remain weak in governance and service delivery. Added to this, potentially emerging regional administrations are, particularly in the central regions, a range of informal clanbased, religious or 'warlord' fiefdoms and various regional 'state-building' projects. In the south, instability is chronic and conflict recurrent and multidimensional, impacted by material, ideological and regional or geopolitical factors to name but a few. Since 2006, following the US-supported Ethiopian invasion into Somalia, a polarisation occurred and today fighting for territory and control continues amongst forces of the Transitional Federal Government (TFG), al-Shabaab, Ethiopian and Kenyan troops, as well as those of AMISOM (the African Union peacekeeping force, consisting of mostly Ugandan and Burundian troops) and a variety of variously allied militia forces. ${ }^{5}$ A powerful war economy sustains this conflict (United Nations Security Council 2011), and spillover to the more stable north remains a worry. Today some 2.5 million Somalis remain in need of emergency humanitarian assistance and the overall situation is increasingly seen as creating a regional, and in certain aspects (terrorism/piracy), a global security threat.

\subsection{Who are the donors, what do they spend, and what on?}

Donors to Somalia are many; the main

'traditional', DAC donors are the USA, European Union (EU), the UK (Department for 
International Development, DFID), Japan, Sweden, Norway, Denmark, and the Netherlands, as well as Switzerland, France and Italy. Of the ten meetings that took place over the last year (May 2011-July 2012), the SDG has 15 donors who attended more than once, and 12 who attended more than half. Their development budgets range from just over US $\$ 1$ million to US $\$ 50$ million annually. Outreach to the so-called 'non-traditional donors', including China, Turkey and the Gulf states, who arguably are playing an increasing role in Somalia, is a professed aim.

Including humanitarian aid, in 2009, official Overseas Development Assistance (ODA) to Somalia was US $\$ 661.65$ million or $\$ 72 /$ capita. This is a conservative estimate because it does not include military aid or other funds outside the DAC criteria, but it nonetheless remains high compared to some other fragile state situations, including Burundi (\$66), Chad (\$50) or the Democratic Republic of the Congo (\$36) although not Afghanistan (OECD 2011).

Moreover, according to the World Bank and most other sources, actual figures are significantly larger, in the range of US $\$ 1$ billion/annually (OECD 2011: 19). Non-Western, or the so-called 'non-traditional' donors, provide significant but difficult-to-trace support to Somalia. Overall aid flows generally have risen and, notwithstanding the global and European financial crisis, are set to increase even further. All but one of the bilateral (Western) donors interviewed for this project indicated that their Somalia aid budgets would increase in future years. ${ }^{6}$

The range of aid budgets among SDG donors is wide. The two biggest are arguably the USA and the EU institutions (the former only if humanitarian aid and various types of military expenditure are added). Indeed, most donors' spending on Somalia is multidimensional. Since the 1980s, humanitarian aid continuously represented the lion's share. Beyond combining humanitarian and development roles, many donors are also active supporters of the war effort in Somalia, be it through training of soldiers (EU), payment of military stipends (Italy, Spain, USA), drone strikes (USA), or proxies such as private security companies, many of which have close ties to the US government in particular. The Netherlands budget, for example, includes only about €3 million development aid but, together with humanitarian (€7.7 million) and other military and piracy-related funds, adds up to close to €29 million annually. Indeed Dutch interest in Somalia has increased exponentially because of the impact of piracy in the Indian Ocean on the port of Rotterdam. Driven more by concerns about global terrorism, US development spending via USAID is about US $\$ 40$ million annually, but as a whole the country spends 'hundreds of millions' on Somalia. ${ }^{7}$ One of these costs is the funding for AMISOM. From July 2011 to June 2012 the UN Security Council and General Assembly spending on AMISOM amounted to around US $\$ 304$ million, the two biggest donors being the USA and the EU.

Beyond such broad figures, it is difficult to say what is being spent where at a given point in time. DID-funded research on institutional support provided to the Transitional Federal Institutions (TFIs) struggled to aggregate figures per year due to the different budget and funding cycles of various donors and the multiplicity of actors involved. With methodological caveats, it noted that in 2010 the total publicly disclosed 'current and ongoing' support to the TFIs in the areas of Rule of Law and Security, Central Institutions, Planning and Finance, Political Outreach, and Local Administration and Recovery was around US\$85 million or more.

When it comes to engagement, larger donors (USA, EU, UK DFID, but not Japan) are also more spread in their engagement, indicating ten or more issue-areas in which they are engaged, as opposed to smaller donors, who indicated between three and eight. All indicated Peace-building (understood in various ways, at local or at national level) and Humanitarian Relief. The next highest ranking were Health, Security and Rule of Law (80 per cent of donors); least mentioned were Infrastructure, Economic Development and Human Rights. When asked to prioritise, all but one indicated 'governance' as central.

\subsection{Nairobi and 'remote management'}

If there is a conceptual case to speak about aid coordination networks as 'intermediary' locations, this is particularly apt in the Somalia context, where almost all of the donor community as well as most implementing partners - and a good part of their elite Somali counterparts - are based in Nairobi (Kenya), practising what is euphemistically called 'remote management'. There are both good and bad 
reasons for this. Somalia remains possibly the globe's most dangerous place for aid workers. In 2008, two thirds of all aid workers killed worldwide were in Somalia (Bradbury 2010: 2).

The persistence of this 'aid community in exile' has become notorious. For many Somalia-based Somalis, the 'Nairobi-culture style' is a pejorative term to underline the lack of engagement with the 'true' Somali context and to describe a network effect in which ideas and priorities are set within the context of specific personal relations rather than Somali 'ground truth'. 'Remote control' is said to reduce tacit and local knowledge. ${ }^{9}$ From the Somali side, donors are not perceived as accountable, while from the donor side the persistence of the Somalia war economy and the lack of transparent financial systems on the part of the TFIs have led to a blame-game on accountability, certainly with regards to South Central Somalia (OECD 2011: 25). The 'transition' context does little to attenuate matters. To Hammond and Vaughan-Lee, the ongoing coexistence of different aid logics and the lack of clear articulation between them have created an all-pervasive 'climate of distrust' (2012: 2). In turn the clamour for 'coordination' is everywhere. In the survey on the implementation of the OECD fragile state principles, 'most actors suggested the need for improved co-ordination to enhance analysis, improve transparency and accountability and move towards in-country joint co-ordination efforts' (OECD 2011: 51).

\section{Defining policy in situ: ambiguity and autonomy} 4.1 Vague policy prescriptions

In conflict and transition settings, actors need to straddle different logics. At the broadest level, most policy prescriptions for external engagement in so-called fragile states insist particularly on two basic ingredients: (1) 'comprehensive approaches' containing multiple objectives, and (2)

coordination. The rationale is straightforward: the various dimensions of fragility, notably political, developmental and security, are interdependent and actors need to avoid undercutting each other or themselves when acting across them. As the OECD fragile states report on Somalia puts it:

The challenges... are multi-dimensional. The political, security, economic and social spheres are inter-dependent. Importantly, there may be tensions and trade-offs between objectives... which must be addressed when reaching consensus on strategy and priorities (OEGD 2011: 62).

Or, in the words of the authors of the World Bank report: 'military-only, justice-only or developmentonly solutions will falter' (2011). The resulting work of identifying and negotiating trade-offs and priorities is intensely contextual and contingent on events. It is also political. The risk is that one part of the 'comprehensive' package will eclipse the others, with negative results over time.

Moreover, in a crisis context, this work must often be done under time pressure, without recourse to a long chain of deliberation.

In Somalia, neither guidelines nor broad narratives provide much guidance. Asked for their guidelines, few donors referenced more than broad agreements at the international level such as the OECD fragile state principles, the Millennium Development Goals (MDGs), or their own country's (global) development policies. Some - Norway, Sweden and Switzerland - indicated work on a future Somalia strategy. Meanwhile, as one donor said: 'We are very invested in the OECD process. But no Somalia strategy. We have donor principles - Paris Declaration, etc. but nobody is really in charge'. One of the biggest donors noted that there are 'no specific documents that we need to refer to. General ODA guidelines but nothing specific to the Somalia issue. It depends on our shoulders.' Another (big) donor referred to a 12-15-page document by its Ministry of Foreign Affairs as being 'very general, no reasoning for why we should do this or that'.

\subsubsection{Conflicting policy narratives and 'umbrella' policies} In broad terms, aid in Somalia has concentrated on provision of humanitarian support as well as efforts to re-establish functioning governance and, unsuccessfully, on traditional 'statebuilding'. Where donor agendas in Somalia are multiple and the context difficult, the guiding effect of grand narratives is limited.

Of course, at the macro-level 'good things' are easily agreed upon: security ('human' and otherwise) and stable structures of governance, including a dignified finish to the latest 'political transition'. Dissent, however, can reign about what this actually means and how to prioritise various goals. The overarching goal of 'statebuilding', much vaunted in the literature on fragile contexts and still part of the basic 
approach to Somalia, has been criticised for disregarding the Somali context and, in its application, helping to maintain an illegitimate political elite that lives off playing the role of formal interlocutors to international actors. Indeed, often a practical tension exists between the insistence on traditional state-building vs approaches rooted in grass roots local governance (Menkhaus 2007; Bradbury and Healy 2010; Leonard and Samantar 2011). Definitions (and practical consequences) of the goal of 'state-building' also differ widely among international actors. In turn, the Somali counterparts do not have a unified vision of a state either (OECD 2011: 11). Indeed the EU Governance Support Framework as written by the Nairobi office now argues that

In the specific Somali context, [the goal of state-building] ... is reformulated as the aim of creating viable public authorities at various levels, which are able to interact peacefully with each other and their citizenry.

\subsection{The role of intermediary level for aid in conflict settings}

Within the context of broad strategies, decisionmaking at capital level leaves wide room for manoeuvre for the intermediate level - in-country aid offices. This is by both intention (decentralised aid) and default. Ansell (2011: 5) argues that the role of intermediate actors in decision-making and influencing change over time grows disproportionately where actors are 'crosspressured between competing institutional imperatives or control attempts': or actors, events or activities are difficult to describe in terms of one specific institutional framework but instead are 'betwixt and between' the cracks of existing institutions or indeed are 'trans-institutional', i.e. straddling institutional boundaries or involved in institutions that may themselves 'interpenetrate' and overlap. Whereas in donor capitals often political and developmental logics are heavily institutionalised and separated by - and coordinated through - highly bureaucratic procedures, in-country these functions are often more fused. This may be at the institutional level, with programmes of institutional or 'governance' support, but is also personnel-driven. Among interviewed donors only UK DFID, USAID and the EU have more than ten full-time staff working on Somalia, with all others between one and five. For some, including Norway, the Netherlands,
Finland, Germany and Switzerland, development (but not necessarily humanitarian) and political functions are combined in one person, creating 'straddlers' that need to mediate and act across political and development logics. The EU special envoy to Somalia combines the post of the senior representative of the new European External Action Service with that of head financial officer for EU Development Aid. Moreover the alignment of possible conflicting imperatives or time frames is often left to ad hoc tactics and negotiation:

While 73 per cent of development partners identified trade-offs between political, security and development within their respective country strategies, only 18 per cent had processes in place to manage such tradeoffs (OECD 2011:37).

Importantly, the fusion of political and development logics is also due to the fact that the distinction between the two spheres, jealously guarded in many donor structures, does not exist for recipient authorities, for whom the allocation of scarce funds remains an intensely political act. Interpenetration of different actors also takes place through the rotating doors that exist for sought-after capable (or Englishspeaking) national staff between donor agencies, recipient administrations and well-paying international implementing partners.

\subsubsection{Policy prescription in situ}

In short, in situations where, on the one hand, institutional or normative frameworks present competing pressures for actors or create lacunae of definition, but on the other hand mutual dependencies are great and not solved by decision-making hierarchies, ambiguities of control and definition are likely to be 'resolved' in situ and at the level of the in-country donor offices or delegations. As intermediate actors they have the opportunity, and - where aid structures are decentralised - the recognised responsibility to negotiate the links between broader international dynamics and local context. In general, aid officials in country offices have a denser web of ties to other donors than that present at the capital level and they channel context-relevant information upward or act as 'sinks' or selective filters for it. They themselves create structures of multilateralism by identifying and selecting implementing partners and disbursement modalities such as 
joint project funds. Arguably over time the priorities and principles developed at this level feed back into national or multilateral policies.

The relative importance of decision-making in Nairobi is reflected in the self-perception of donor representatives. Most felt that they had high autonomy over decision-making either because they wrote their own strategy or because they had a big influence over it by identifying relevant projects and being responsible for their evaluation. Some, such as Sweden and the Netherlands, were just in the process of getting more formal responsibilities and autonomy over allocation. The EU was more hesitant, pointing to lengthy internal procedures in Brussels, but still indicated that ultimately strategies and project identification was done at Nairobi-level. Moreover, given that formal 'crisis procedures' apply to Somalia, the delegation is able to enter into direct agreements with implementing partners when deemed necessary without having to go through a tender process or a call for proposals. Moreover, the EU Special Representative for Somalia acts as the National Authorising Officer (NAO) on behalf of the Somali authorities and thus the project approval process remains in-house.

Most donor representatives, but also the UN actors interviewed, felt fairly comfortable with their authority to make day-to-day decisions and thought that external control over their work was rather low. For the Resident Coordinator's office, such control was seen as higher in the humanitarian field than for development. For most, if external control was exercised, it was only sporadic, and, for some but not all, politically motivated. This brought its own problems. As one major donor put it: 'Sometimes it is highly intense; sometimes not at all. Because it's sporadic it's more problematic, because there is no proper shared body of knowledge and nobody who follows things continuously'. Another donor felt that there was almost no external control but at times high-level statements from the capital could suddenly throw up new work programmes.

\section{Coordinating policy in the absence of a mutually recognised coordinator}

Given the above conditions, Nairobi-based aid coordination sometimes is, and to many should more often be, a crucial means to help provide content to a fluid policy context and could help make crucial decisions about aid in Somalia. There is indeed no shortage of coordination mechanisms; the benefits of coordination, however, seem to remain elusive. Indeed, the 'plethora of fragmental international coordination mechanisms and few joint (nationalinternational) co-ordination mechanisms' are seen as a problem by all those participating in the fragile state survey (OEGD 2011: 14).

Three main, often overlapping, avenues for coordination exist: through joint strategies, through formal coordination bodies and systems, and informally through ad hoc 'club' type solutions. Each is discussed in turn.

\subsection{Coordinating by strategy}

The most expansive of these is probably the Reconstruction and Development Programme (RDP), itself the result of a two-year Joint Needs Assessment (JNA 2004-07) led by the UN and World Bank. The RDP, costed at US $\$ 2.2$ billion over five years, was to present a comprehensive framework to move from crisis recovery to development and 'reconstruction'. At a cost of US $\$ 4.2$ million, the JNA involved some 136 experts, half of which were Somali, and included consultations across Somalia (CISS ExCom n.d.).

Most donors engaged in the process as well as the UN system nominally committed to the RDP. It informs the EU and Norway Joint Strategy Paper (JSP 2008-13) and the United Nations Somalia Assistance Strategy (UNSAS). However, the five-volume consensus document did not provide for prioritisation of activities and was rampantly holistic. As one participant and major donor put it, 'It contained every sector, sub-sector of engagement possible. Hence, alignment has occurred by default... mostly because everything was there in the document to align to.' While participatory in the process, it did not necessarily improve relations among the major actors. It 'contributed to raise expectations without limits, leaving donors to deal with such heightened expectations'. As acknowledged by a UN reflection paper in 2012:

Within the context of ongoing conflict and continuously conflicting imperatives the RDP failed as a practical programming tool. It was also widely seen as being heavily influenced by the UN agencies' desire to reflect their natural programming affinities (CISS ExCom 2011). 
In short, there was ultimately little real buy-in and no consensus on how to act. The deeper problems of ownership and the recurrent, but over time varying trade-offs between core objectives, remained procedurally and substantively unaddressed. The UNSAS plan is equally difficult to disentangle. On the one hand it affirms the principles of humanitarian actions as independent from any other occurrences but on the other, it equally urges all action to be supportive of peace-building, i.e. de facto a political process (see Hammond and VaughanLee 2012: 9).

If the RDP should have been owned by Somali authorities and international actors, this was not to be. By 2012 Somaliland had prepared its own National Development Plan (with support by UNDP) for which it sought donor alignment, and Puntland's was in preparation. For South Central Somalia and the TFIs, the officially relevant strategy paper became in 2011-12 the 'Roadmap to End the Transition'. The Roadmap was adopted in September 2011 and co-signed by the so-called 'principals' - key Somali politicians. It lists the key tasks that the TFIs should undertake with donor support in order to complete the 'transition' by August 2012. ${ }^{10}$ Operationally, the Roadmap is supposed to be supported by a Joint Security Committee and four technical working groups consisting of donors, UN and Somali counterparts. Yet even this document, benefiting from high-level political attention, arguably failed both in implementation and as a fundraising tool vis-à-vis donors, largely due to what was seen as excessive costings. Prioritisation at the end of the transition was driven by what was (more) easily achievable rather than by agreement on what was most important (see below) and its committee structure never took off.

\subsection{Coordinators: government, multilaterals and formal bodies}

Making and implementing strategy among a set of heterogeneous actors subject to a multitude of pressures and priorities is ultimately an act of continuous interpretation. Agreement on precise texts is difficult and most strategies will reflect that fact. In this context, ongoing coordination is required both to interpret and prioritise, and to provide forums of accountability, whether between peers or across different types of actors. Reflecting this need, lack of effective coordination is a widely recognised problem of all participants in the Somali aid community. Equally reflective of this need is the abundance of coordination structures in Nairobi. Respondents listed a total of 20 different working groups and bodies they themselves participated in, which still remains a conservative estimate. Yet all are characterised by (a) the relative absence of Somali interlocutors; (b) a declining influence of the UN agencies; (c) an uneasy distinction between 'political' and 'technical', 'development' and 'humanitarian issues'; and (d) a general tendency of donors to call for coordination, complain about the multiplicity of related fora and arguably fail to seriously commit to any of them.

\subsubsection{Coordination through 'counterparts'}

This article concentrates on coordination between donors. Yet under 'best practice' this coordination should be steered by national authorities taking the lead in organising the many actors that try to help them improve their affairs. Capacity issues on all sides, as well as a host of other relational factors - notably pervasive distrust - mean that such processes barely function, even where tried. First of all, in Somalia, the necessity to engage separately with the different 'entities' means that any donor coordination efforts, be it with each other or with counterparts, need to be multiplied by three. For many donors staffing issues make this difficult. Moreover, the low administrative capacity of Somali authorities and the low trust among donors and counterparts means in general aid is not aligned with (in any case, largely nonexistent) national systems. As a result, planning processes are rarely joint and almost all donor programmes are implemented though UN or international non-governmental organisations (NGOs) or other parallel project implementation units, again multiplying the number of policyrelevant actors.

Especially with regard to the TFIs, the absence of a credible interlocutor is keenly felt. Where discussions with their representatives about institutional support take place, they are often highly abstract. Due to problems of access and their location in Nairobi few donors have actually seen the institutions they debate, and rumours about their Potemkin-like nature abound (and are frequently confirmed). For instance, in 2010 during a number of meetings of the UNDPfacilitated 'stipend task force', which turned around support packages for core ministries, the 


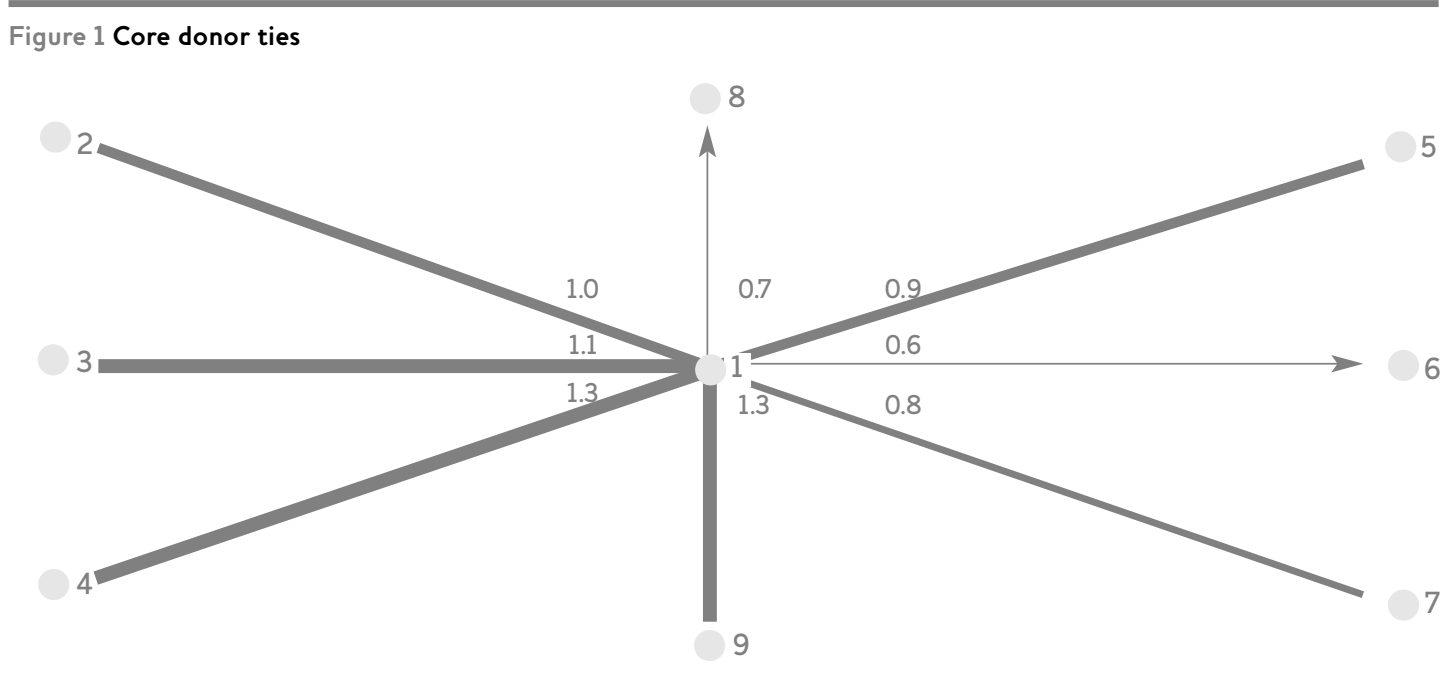

government bargained hard around the number of 'core staff' it wanted supported. Then one of its own representatives interrupted noting that the discussion seemed surreal since all these administrative structures that were talked about did not 'really' exist: 'You have no ministry, minister'. Similarly, after years of UN support for the Somali Central Bank an external evaluation of the relevant programme noted that it was 'an institution in name only' fulfilling none of the functions of a Central Bank (Thery and Amici 2012). A 2010 DFID-led attempt to place technical assistance into the TFG Ministry of Planning to facilitate donor coordination and aid management brought little result, in part due to lack of access. As an answer to such issues, the Somali donor community seems to have taken the position that country-led coordination is not an option and retreated to very punctual and symbolic interaction with its counterparts. The network images show this starkly. They are based on respondents ranking their interaction with various international or Somali actors (minimum 0: no interaction; maximum 3: close interaction). Interaction with both UN actors and other donors is significantly more frequent than with government counterparts.

Figures 1 and 2 collapse all actors of a specific type into nodes or 'blocks' and show the average strength of connection between blocks, i.e. of actors of one type with that of another type (possible minimum $=0$, possible maximum $=3$ ).

Figure 1 focuses on core donors interviewed (node \#1). This block's strongest connections are to each other (in-block average 1.9). This is followed by linkages to block \#4 (UN agencies, average 1.3), other donors' political offices (\#3) and other development donors (\#2). The right side connections are comparatively weaker, indicating the relative weaknesses of interaction with TFG authorities (\#5), Somaliland authorities (\#7) and, weakest, Puntland authorities (\#6).

Figure 2 shows the same for the UN actors interviewed. In-block ties are strongest and comparatively stronger than that of the donor block (average in-ties 2.83), in part driven by a level of organisational integration as part of the UN family and the Integrated Strategic Framework. Ties to core donors (\#4), political donor offices (\#2) and other UN agencies (\#3) are relatively equal with ties to regional or central authorities. The strongest connections are to the TFIs (\#4), followed by Somaliland (\#6) and Puntland (\#5).

Together these images suggest that donors are highly unbalanced in their interaction, focused on peers and UN agencies, whereas UN agencies are more evenly balanced, with strongest ties to the TFIs. This reflects their role as intermediaries between international development donors and recipient institutions, as well as the larger attention paid to Mogadishu institutions to the detriment of the more stable North.

Beyond sectoral meetings in areas such as in health and education, which take place every three to four months, and some project-specific 


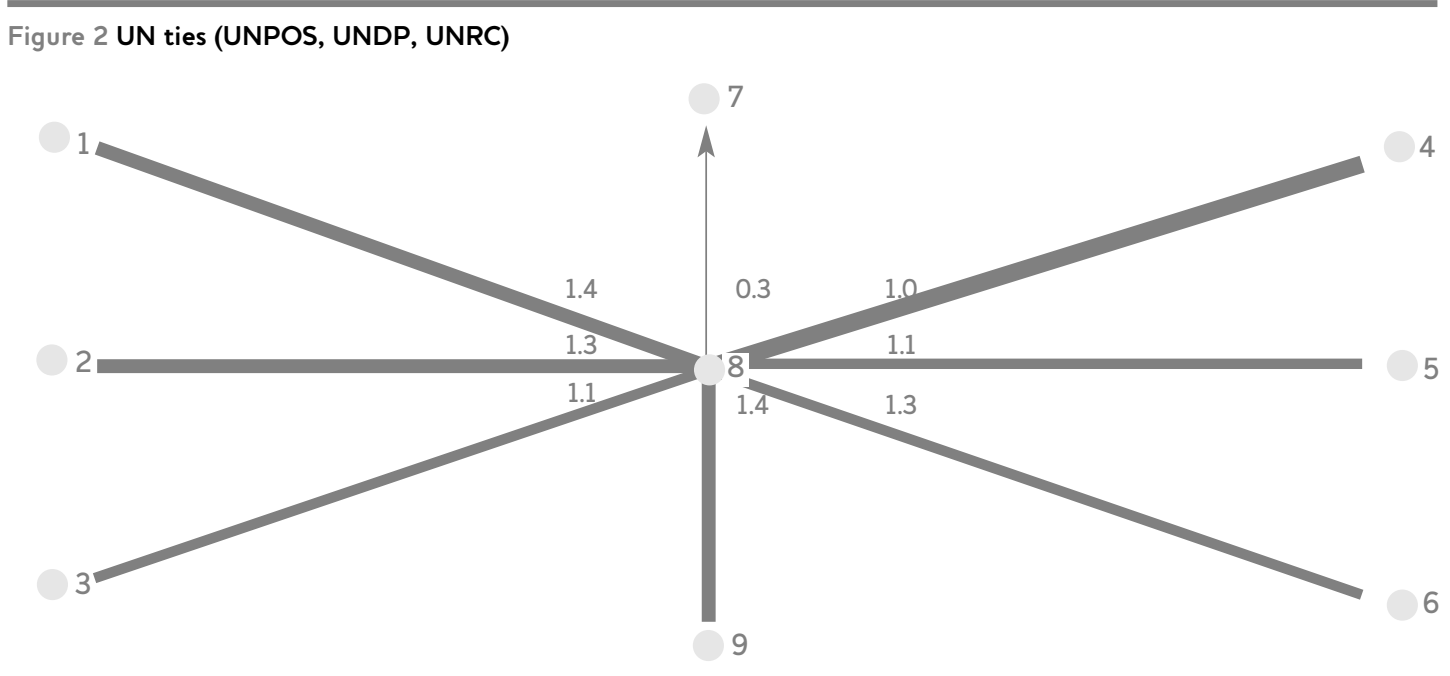

board meetings, no regular coordination structures exist in which donors and government representatives meet. A high-level aid dialogue was launched in Somaliland but remained embryonic at the time of writing. The UNmanaged committee-structure of the Roadmap process failed to be implemented. On 'good governance' one trilateral meeting took place but remained a one-off. Interaction with government actors is thus ad hoc and rare for most donors. Ties are weak in substance and in frequency. Asked to rank the level of their collaboration with government actors, other donors, and the UN system, SDG members consistently ranked collaboration with government actors lowest. One explained:

When I first came here I wondered 'Who are we coordinating with?' Now I don't ask that question anymore. We have no counterpart... In Somalia with the High Level Aid Coordination forum - the

Somalia donor group is trying to take this seriously but there has not yet been impact on my decisionmaking... in South-Central there is nobody to talk to seriously.

Notably only one (major) donor believed collaboration with government was more valuable for its work than collaboration with the UN system, mainly because it was adverse to channelling money through the latter. For all others the relationship was inverse. In the words of one interlocutor: 'It should not be like this, but it is'. Another of the major donors explained its minimum level of interaction with government bodies in terms of its choice of partner: 'We fund through UN agencies and tell them to cooperate with Somali authorities'. The next section reviews the role of UN actors as mediators, implementers and interlocutors.

\subsubsection{Multilateralism in organisational form - coordinating through UN agencies}

As noted earlier, organisational multilateralism is one way to tackle coordination problems. The UN plays a prominent role in Somalia both politically, through the offices of the UN Political Office for Somalia (UNPOS), led by the Special Representative of the Secretary General, the role of its Humanitarian and Resident Coordinator (HC/RG) and through the large presence of its specialised agencies implementing both in the

Figure 3 Average perceptions of degree and value of collaboration with donors, the UN and Somali authorities respectively (scale 1-5)

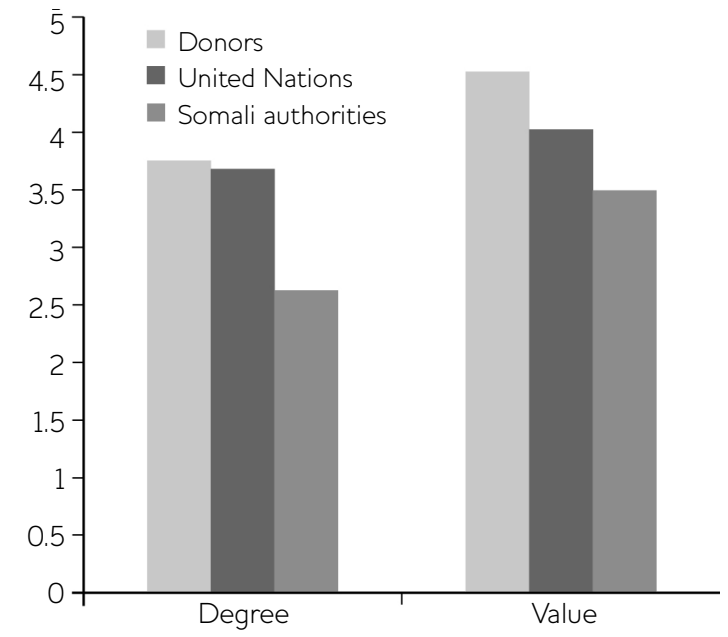

IDS Bulletin Volume 44 Number 1 January 2013 
humanitarian and development field. Almost 100 per cent of the considerable Japanese aid to Somalia is channelled through the UN, as are 80 per cent of the Netherlands' humanitarian funds and 50 per cent of its spending on governance. Figures for most other donors interviewed are roughly similar. The EU channels 35 per cent of its overall spending through the UN but does so disproportionately in its institution-building and governance portfolio. The USA and, less so, UK DFID buck this trend, having reduced their development funding via UN agencies over the last years.

In 2012 the instruments used were multi-donor programmes, a number of joint agency programmes or pooled funds, and three currently existing Trust Funds, of which two are managed by UNPOS and one is the Common Humanitarian Fund, managed by the UNRG/HC.

The duality of UN roles, as implementers and as brokers for coordination can cause problems. One is the patchy record of implementation. Consecutive reports of the UN Arms Embargo Monitoring Group for Somalia have raised issues of transparency and management with regards to mostly humanitarian but also development projects. The high reliance on UN actors for implementation coupled with little in-country oversight has increased both justified criticism and unjustified scapegoating. At the same time UNPOS is widely criticised as both highly politicised (read: biased) and lacking capacity. In turn many of the Somali authorities and donors express dissatisfaction with the UN agencies as both implementers and convenors of policyrelevant dialogue. One key donor, while ranking collaboration with the UN quite highly, ranked the value of this collaboration as minimal 'because they just don't deliver'. In addition, internal divisions mean that much energy is spent on internal coordination and alignment. As one interlocutor put it with regards to coordination:

There is no real structure and no lead. The Resident Coordinators Office should do this and be allowed to do it, but it can only happen if there is more integration and the humanitarians come on board. ${ }^{11}$

\subsubsection{Formal coordination bodies}

In this context formal coordination structures are an ongoing project. Beyond sectoral ones, a set of 'political' bodies exist alongside two principal multi-sectoral 'developmental' ones. The latter were once again in the process of reform during the time of writing. Both are offsprings of the Somalia Aid Coordination Body (SACB) which was founded in 1993 and which was uniquely based on bringing together three types of actors UN bodies, NGOs and donors (Von Hippel 2007). In 2005, the SACB transformed into the Coordination for International Support to Somalia (CISS) bodies whose executive committee is co-chaired by the HC/RC and the World Bank. In 2011 its support secretariat was disbanded and some functions transferred to the Resident Coordinators Office. A current Aid Effectiveness Secretariat (AES) consists of one person and supports the SDG, which brings together all interested donors, with the $\mathrm{HC} / \mathrm{RC}$ as well as UNPOS as observers. ${ }^{12}$ It is noteworthy that, possibly because of the absence of coordination through government, UN and donors have historically vied for dominance in coordination structures for Somalia (Von Hippel 2007).

\section{(a) Coordinating 'development': SDG and CISS ExCom} The SDG is a soft and voluntary coordination structure that holds regular (monthly), wellattended meetings. Its mailing list includes over 90 individuals, while attendance at meetings averaged 13.5 between May 2011 and July 2012. A relatively stable group of some eight core donors plus UNPOS and the RCO attends more than 80 per cent of meetings. Participants see it as necessary but not necessarily effective. 'You sit together and meet colleagues but [it is] not a useful vehicle; more of a loose happening'; 'The agenda repeats other meetings and there are no conclusions'. The SDG does not engage in joint programming discussions which, if at all, take place outside the forum on an ad hoc basis and it takes no joint or binding decisions (but has written joint letters of concern), and its co-chairs perform representative functions vis-à-vis government authorities, notably in the emerging dialogue with Somaliland. The fact that the SDG is primarily about information sharing and does not take decisions means that participants are not required to prepare for the agenda, arguably impacting on the quality of discussion.

The main challenges recognised include those of internal reform and possibly sub-structures, engagement with 'non-traditional' partners, and outreach into Somalia. Another is engagement 
with the 'political side', i.e. the deliberations taking place among political representatives of donors and UNPOS. Some tension about the participation of the UN in the SDG also exists. As one respondent put it: 'The SDG should be more for donors to discuss and align and then we can bring that into the CISS; not invite UN and NGOs to SDG'. The CISS ExCom meetings, whose membership overlaps with but is more restrictive than the SDG, was seen as relevant but again issues of mandate, decision-making power and overall relevance were raised. In the words of one of the more critical interlocutors: 'It's not going anywhere. It's like people attend not because they expect something but [because] they say "Let's go through that rather than having to figure out what we're really doing"'. Overall, respondents to the OECD survey on fragile states acknowledged that formal coordination had no or only marginal impact on agreement on objectives. And yet, discomfort with existing mechanisms is not reflected in a clamouring for more binding ties or processes while criticising its loose nature, most respondents effectively described the SDG when asked about the characteristics a formal coordination body should possess. ${ }^{13}$

\section{(b) Coordinating diplomats: political fora}

The 'P3 +' meetings - gathering three permanent members of the Security Council (USA, France and the UK) plus a number of other Western diplomatic missions and UNPOS - is a regular 'political-level' coordination body with large informal elements. Based on a club model, participants are selected by a somewhat diffuse process of status recognition. It has regular and well-attended meetings but no permanent structures, is chaired by each meeting's host and no minutes are taken. It does sometimes conclude action points or agrees on messaging vis-à-vis counterparts, including a certain division of labour in that respect. Wielding some concerted power, it is seen by most of its participants as the body that most influences their decision-making (only one, major, donor stated that coordination bodies, including the $\mathrm{P} 3+$ were merely 'a confirmation of our polices, we use them to gain consensus, influence others'). It is seen as a crucial body for UNPOS, both to pass messages and to align with major donor interests. As a body that understands itself as purely political, the interaction with the other more developmentoriented fora is indirect through de facto overlapping membership. Examples are Norway and France, which only have one person for both functions, and the EU, whose representative is the head of both the EU development arm and the representative of the EU External Action Service. It also occurs through the messaging that more technical programme or project-specific steering groups receive from the $\mathrm{P} 3+$. This general interaction is not always without problems, notably when political interests in Somalia increased drastically with the run-up to the key transition dates. Given that the P3+ rarely discusses project-related issues unless considered directly politically relevant, adequate information flows are not structurally given. In the management of the highly sensitive donorfunded constitution-making process disagreements and friction with the implementer, a Joint Unit of UNDP and UNPOS were at times exacerbated by the latter's success in participating directly in $\mathrm{P} 3+$ meetings. This created a dynamic in which the $\mathrm{P} 3+$ was seemingly green-lighting processes that had been critically discussed at the technical 'development' level. While in part based on a difference of priorities between political and development actors, the resulting problems of management were also due to the ability of one implementing actor to play off the gaps in information exchange and coordination between different elements of donor engagement.

In summary, what is notable in the Somali coordination structure is that the 'Roadmap to End the Transition' was the only strategic framework that (a) included different types of actors - agencies, government and donors - and was, at least in theory, (b) anchored in regular formal coordination processes at both technical and political level. ${ }^{14}$ As noted above, however, the Roadmap committee structures never really took off and the close timelines of the transition became the dominating theme of the Roadmap as a whole. ${ }^{15}$ In addition, there is no general coordination structure that incorporates systematic discussion around one of the key concerns of donors and government actors, exacerbated by the reality of 'remote control', namely processes of aid impact assessment, indicators, monitoring or evaluation or shared analysis of process variables.

\subsubsection{Ad hoc and informal ties}

Not surprisingly given this broader context, ad hoc and informal coordination mechanisms dominate 


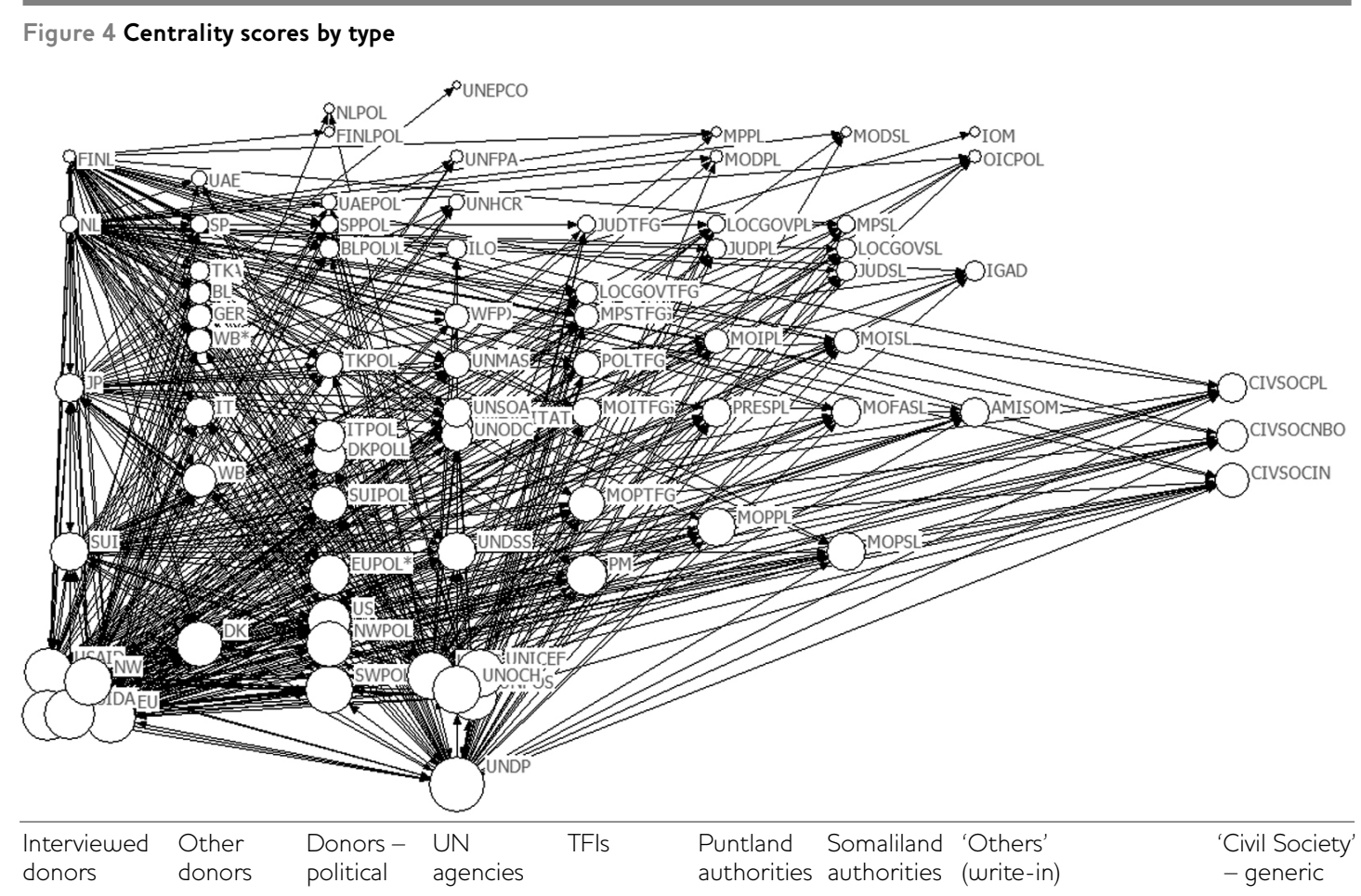

Note Some actor nodes have been artificially separated from each other to reveal them more clearly in the image. Note therefore that the dense group of donors on the bottom left all share the same in-degree centralities, as does the dense group of UN agencies above the UNDP node.

the coordination activities of donors to Somalia. Almost by tautology, these processes are seen as more effective by those who participate in them. They are self-selected and sought out when actors are motivated for it and look for specific solutions to concrete problems. This corresponds to assumptions that the informal is more flexible and allows information to flow faster whilst having low 'sovereignty costs' - no public or binding commitments are necessary. Voluntariness allows for exit and flexibility maintained.

Specific issue-areas in which informal consultations have been particularly useful were the constitution processes. The other area, not unexpectedly, was security sector assistance. The prevalence of informal connections in decisionmaking draws attention to the centrality scores indicated by the (limited) network mapping conducted. Given this network is only a partial mapping (only a small subset of actors were interviewed) the analysis is necessarily partial. What is interesting in this respect is that key donors' centrality scores (on the y-axis of Figure 4) are, as could be expected, higher than those of smaller donors, but not necessarily significantly so. In part this may be a result of the fragile state scenario where the ability to disburse money flexibly and quickly provides specific donors with key roles in processes that often change quickly. Norway is one example of this trend. The scores also show that very small actors, such as Switzerland, may play roles that are more prominent than the monetary size of their portfolio suggest.

To visualise the above, Figure 4 groups all actors mentioned in the survey instrument by type (on the horizontal axis) and locates them on the vertical axis according to their in-degree centrality. The more the interviewed actors indicated ties to a specific actor and the stronger these cumulated ties (1-3), the lower they are situated on the vertical axis and the bigger is their respective node.

One issue area of great concern has been about alignment on various Principles of Engagement across Somalia in line with a 'do no harm' principle anchored in the guidelines for 
engagement in fragile states. While initiatives were launched first in informal discussion, they tended to slow down drastically when a degree of formality was introduced. Within the humanitarian community, Joint Principles or 'red lines' were proposed in 2008-09 to define how humanitarian principles could be upheld in the Somali context. While mentioned in a number of documents, the principles never became official, in part because they would be breached in the daily (bilateral) negotiation of access and operational space by most actors (Hammond and Vaughan-Lee 2012: 12).

On the development side, a related attempt at Joint Principles for 'engagement with emerging areas' is still ongoing and concerns the attempt to bridge 'stabilisation' (security and political) and development (long-term governance) priorities and approaches with regards to potential or real sub-national administrative authorities clamouring for assistance. While this discussion was both pushed by the Resident Coordinator's office as well as - in a different form - by a key bilateral donor, the UK, after 18 months of debate there is still no basic consensus on either the principles or the venue to discuss various rationales for engagement of the different programmes concerned. The plan for a future multi-donor 'stability fund' to be set mainly through UK DFID (80-90 per cent of total projected contributions), lists a number of principles for engagement but also indicates that these will be applied in highly flexible ways and not necessarily all at the same time. What remains is arguably a lack of joint engagement with the notion of 'do no harm'. Stabilisation programmes have had mixed records in other contexts (Fishstein and Wilder 2012) and there is no shared understanding of the trade-offs that may have to be made in the Somali context between short-term objectives of using them to open a door for dialogue with 'actors on the ground'; for dialogue between these actors; to reduce the likelihood of immediate conflict by impact on 'triggers'; or to create either short-term or longterm economic prospects that would address some of the structural root causes of conflict.

\subsubsection{A Nairobi effect?}

Most of the issues and challenges of coordination, including the structural properties and relationships that underpin it, do not, at first sight, seem heavily conditioned by 'remote control' management or the Nairobi site. And yet it is seen by most, if not all, interlocutors as a key stumbling block for better aid coordination. What impact would a move in-country have on donor coordination?

Interlocutors noted a number of issues related to the Nairobi site: at a broader level, the attractiveness of Nairobi is seen to reduce staff rotation and thus maintain 'business as usual'. Also, 'People don't leave Nairobi; they just reinvent themselves in new jobs. It would be good to have some comparative thinking, different experiences.' Conversely, long experience with Somalia is also seen as a benefit, and thus judgement here may be more individualised than structurally justified. However, undoubtedly, relocation would imply large organisational change for many actors, changing staff composition and lines of authority and, crucially, shortening the chain from impact assessment to programme planning. This in turn would alter relationships between the UN system and donors and the government.

The disconnect between information about implementation and impact of programmes is a related issue, not just for implementing agencies. Arguably for many SDG members frustration with coordination activities was high because it was diffusely felt to be a displacement activity, disguising the lack of actual engagement with monitoring and planning on the ground. Some interlocutors thought that presence incountry would change the priorities of aid programmes: 'If you're in the country Somalis are in your face more. I am sure there would be more investment in infrastructure... Political engagement would change.' A larger focus on the impact of aid would also, it was argued, depersonalise some of the conflicts or tensions that exist in the larger aid community, basing it more on 'reality' - 'bad communication is exacerbated by the lack of knowledge and the remote control setting'. It seems a fair bet that the Somali population as a whole would ultimately benefit.

There are, however, limits to the blame that can be put on geographical distance with regards to all that is, to many, frustrating about Somalia aid delivery. Not least is the fact that many issues, including improved joint monitoring and evaluations are geography-sensitive but not geography-determined. Moreover, important 
problems of access would remain even after relocation. Other issues of donor coordination, such as the parallel role of non-traditional donors would remain largely unaffected by relocation to Somalia. In the words of one major donor: 'It's remote control but everybody is here. The non-traditional donors would not be in Mogadishu either. They are in their capitals. The only donor who is there is Turkey.'

Whereas a push for relocation would enable closer linkages to Somali counterparts of all types, some respondents also noted that the notion of the 'Nairobi mafia' was much more an issue for interlocutors from South Central Somalia than Somaliland or Puntland:

'Somaliland and Puntland complain less because they have the capacity to be more involved'. Inversely some donors acknowledged that the relationship would not automatically improve through common geography since distrust and lack of transparency among various actors would arguably travel along. One smaller donor noted that they were 'not sure one would not be instrumentalised in-country; it might be even more hectic'. And a major donor compared the situation to a previous posting: 'Wherever we are, we all operate in a bubble with a lot of manipulation'.

\section{Conclusions}

The Somalia case showcases many of the wellknown issues with engagement in conflict states the boundaries between development, security, 'politics' and pure 'humanitarian' interventions are difficult to define, if they exist, and certainly are not stable over time. Actors affect each other most of the time and operate under conditions of high interdependence, without one being dominant. The 'intermediate' level of Nairobi, including the values and norms that are emphasised, also clearly plays a key brokerage role to the respective capitals. Following Ansell's theoretical work (2011), the prevalence of the 'betwixt and between' scenarios both for actors and policy challenges presents large opportunities for creative engagement, innovation and bricolage, and change. But the platforms for such action to develop and be recognised are few.

Almost all actors and certainly most observers will confirm the necessity of coordination in the common interest of individual actors, and yet formal coordination remains generally weak, non-binding and elusive. 'Development' actors see coordination as weak and it is certainly a recurring problem between the 'development' and 'political' spheres. On the other hand, humanitarian actors and donors have retreated behind humanitarian principles, a separation that arguably comes at the cost of overall 'systemic' learning, especially where humanitarian and development activities (and actors!) overlap over decades, notably in South Central Somalia.

With regards to government authorities, there is a great paradox. At the macro level much criticism has been heaped on Western countries' insistence on maintaining the legal fiction of a Somali state government when the current Federal Government is in almost no way a functioning administration and to many a government in name only, propped up in part by other states' needs for a 'functionally equivalent' interlocutor, virtual or not. Yet when it comes to aid management the approach, facilitated by the Nairobi location, has been to wait for the fully functioning interlocutor. The middle ground, the attempt to build capacity for public policy (at whatever level) during engagement, is only found in project-specific dynamics, and only rarely. It would arguably be a crucial part of any coherent strategy of engagement.

At the multi-sectoral level, divisions persist as to who leads coordination and through what means. Meanwhile, coordination efforts that are effective in jointly reducing policy ambiguity and defining necessary trade-offs in competing priorities tend to be driven by ad hoc and personalised mechanisms. It is part of a familiar catch-22: where actors are already aligned, informationsharing can be sufficient coordination to improve learning and increase collective impact. Where this is not the case, more robust coordination is needed. But where differences exist, robust coordination may not be pushed far enough.

One key victim, particularly in more turbulent contexts is accountability and learning.

Coordination is a source of peer accountability, the result of evaluations of organisations by their counterparts, in short a pressure to behave better (Grant and Keohane 2005). Yet the more informal, or the less coordinated, the more difficult for national counterparts as well as outsiders and insiders to understand the mechanism of aid. 
Looking at existing interaction mechanisms in the Somali donor community in terms of actual relationships and networks provides some insight into how strategies are pursued and what types of peer-accountabilities exist.

What appears here is a set of relationships that are fundamentally about the exercise of influence. Connections exist bounded by a very broad subject area - engagement in Somalia and are shaped by geographical reality as well as the broader Somali context. While conflict among actors is not excessive, in the absence of joint analysis and definitions of key priorities, competitive logics are maintained and there is ultimately only a very broad shared ideology at a high level of aggregation ('development', improving Somalia, fragile state principles). Shared professional standards exist in sectoral sub-systems but do little to inform broader strategic planning (with the possible exception of the humanitarian field).

For actors, both fragile state characteristics and their relationships affect power resources. The size of a donor's budget does not translate directly into influence. Pure financial weight can matter, but so does the ability to disburse flexibly and quickly. By extension the appetite for risk also determines clout at a specific time. Of course, badly assessed risks undermine the latter over time. In addition, fora for substantive coordination are based on entrepreneurial dynamics, not on formal structures, thus benefiting those with the capacity and will to

\section{Notes}

1 This includes the eight most permanent members of the SDG, representing six of the ten biggest ODA donors to Somalia between 2009-11 listed by OECD-DAC (of the remaining four, Germany and Spain lack development representation for Somalia in Kenya, and Denmark was not available. The last is the Global Fund for HIV/AIDS). Added to this were the UN Political Office for Somalia, the UN Humanitarian Coordinator/Resident Coordinator for Somalia, and the UNDP Somalia Office.

2 This distinction is somewhat simplified as both the ends and means of humanitarian and of development aid are diverse and can overlap.

3 These include the BTI (Bertelsman Transformation Index) of the Bertelsman engage in coalition-building. Often, creative and successful coordination can occur based not on multi-sectoral agreements but programmespecific engagement that over time can be replicated in other areas. Donors who are engaged in many areas are more likely to be the conduits for this. Differences in approaches will persist due to the heterogeneity of all actors and the multiplicity of interests involved. In such a situation arguably too much coordination (or centralisation) would be as undesirable as too little. Yet the former is arguably so unlikely as not to be a real risk whereas the latter is a widely perceived - if not widely addressed - problem.

Despite much distrust, UN agencies provide a gatekeeper function vis-à-vis Somalia counterparts. The internal division and perceived biases of key UN institutions, combined with their multiple roles make their task a difficult one. They do constrain donor behaviour, influence their room for manoeuvre, and provide a broker role between donors and Somali interlocutors. Yet this has also negative effects, and is not always seen as conducive to common approaches by all sides, which has meant that multilateral principles are difficult to 'settle'.

Trilateral dialogue about aid, including Somali counterparts, donors and the UN system remains largely symbolic and at the diplomatic level. This lack of joint engagement based on publicly traceable 'technical' principles undermines both accountability and joint learning over time, in turn impacting trust, a potential resource for reform.

Stiftung, the Fragile State Index at the University of Maryland, the Index of State Weakness at the Brookings Institution, and the State Fragility Index (OECD 2011).

4 Until August 2012, the 'Transitional Federal Institutions' were Somalia's nominal government. They had no capacity to fulfil basic government functions and were riddled by internal division. At the time of writing, the end of the transition in August 2012 did not change either circumstance.

5 In 2012 AMISOM forced the al-Shabaab out of Mogadishu and other population centres in Southern Somalia.

6 UK DFID is almost doubling its budget, Switzerland is engaging with a serious portfolio from 2013 onwards, while the EU has boosted its aid envelope with an extra $€ 175$ million to 
come on stream in early 2013. Germany and Turkey are among new and significant donors.

7 Interview with USAID Somalia, Nairobi.

8 Norris and Bruton (2011: 23) show that the USA has provided over US $\$ 185$ million to AMISOM between 2007-10 and the EU some $\$ 297$ between 2007-11. The USA has also spent considerable sums paying the soldiers of the TFG.

9 According to Puntland authorities the average days spent in Garoowe per year by UN Country and Deputy Country Directors was three to four days each, with only five individual or joint donor visits in 2010 (OECD 2011: 23).

10 Somalia 'End of Transition Roadmap', http:/unpos.unmissions.org/Portals/UNPOS/ Repository\%20UNPOS/110906\%20\%20initialled\%20Roadmap.pdf (accessed 15 October 2012).

11 Argument persists on greater 'structural integration' (NRG n.d.). Some argue that after 20 years of engagement, humanitarian actors are deeply implicated in Somalia and

\section{References}

Alesina, Alberto and Dollar, David (2000) 'Who Gives Foreign Aid to Whom and Why?', Journal of Economic Growth 5.1: 33-63

Ansell, Christoher K. (2011) 'Institutionalism and Ecological Explanation (draft manuscript)', World Development Report 2011: Conflict, Security and Development, Washington DC: World Bank

Bradbury, Mark (2010) Statebuilding, Counterterrorism and Licensing Humanitarianism in Somalia, Medford MA: Feinstein International Center

Bradbury, M. and Healy, S. (eds) (2010) Connecting Somali and International Peacemaking, London: Conciliation Resources

CISS ExCom (n.d.) Summary of Process, Key Facts and Figures for 3 May 2012 Initial Consultations on a Future Aid Framework for Somalia, Somali Joint Needs Assessment and Reconstruction and Development Programme

CISS ExCom (2011) Issues Paper Joint Development Planning Frameworks June 2011, prepared for the Somali Donor Group and key development partners

Elkins, Zachary (2009) 'Constitutional Networks', in Miles Kahler (ed.), Networked Politics: Agency, Power and Governance, Ithaca: Cornell University Press: 43-66

Fishstein, Paul and Wilder, Andrew (2012) Winning Hearts and Minds? Examining the should engage in broader debates about capacity-building, access and the role of aid in the Somali war economy (Hammond and Vaughan-Lee 2012).

12 Humanitarian coordination mechanisms are not discussed here.

13 All agreed that formal coordination bodies should be able to hold regular meetings; most thought it should have ad hoc staff.

Respondents were in slight favour of joint decisions but most wanted these to be based on unanimity. All UN actors interviewed and less than half of bilateral donors thought coordination bodies should have permanent staff.

14 The CISS was supposed to be the organisational anchor for the RDP but failed in this regard.

15 The Roadmap process was initially linked to donor efforts to define clearer benchmarks for support. Yet given the nature of the progress reports and the dormant committee structure, it failed to provide such a platform.

Relationship between Aid and Security in Afghanistan, Medford MA: Feinstein International Center

Grant, Ruth W. and Keohane, Robert O. (2005) 'Accountability and Abuses of Power in World Politics', American Political Science Review 99.1: 29-43

Hammond, Laura and Vaughan-Lee, Hannah (2012) Humanitarian Space in Somalia: A Scarce Commodity, London: Overseas Development Institute

Harper, Mary (2012) Getting Somalia Wrong? Faith, War, and Hope in a Shattered State, London and New York: Zed Books

Hjertholm, P. and White, H. (2000) Survey of Foreign Aid: History, Trends and Allocation, Discussion Papers 00-04, Univerity of Copenhagen, Department of Economics Leonard, D. and Samantar, M. (2011) 'What Does the Somali Experience Teach us about the Social Contract and the State?', Development and Change 42.2

Macrae, Joanna and ODI (2002) Uncertain Power: The Changing Role of Official Donors in Humanitarian Action, Humanitarian Policy Group Report 12, London: Overseas Development Institute

Menkhaus, Ken (2010) 'Diplomacy in a Failed State - International Mediation in Somalia', in Mark Bradbury and Sally Healy (eds), 
Connecting Somali and International Peacemaking, London: Conciliation Resources

Menkhaus, Ken (2007) 'Governance without Government in Somalia: Spoilers, State Building, and the Politics of Coping', International Security 31.3: 74-106

Norris, John and Bruton, Bronwyn (2011) Twenty Years of Collapse and Counting: The Costs of Failure in Somalia, Washington DC and Broomfield CO: Center for American Progress and One Earth Future Foundation

NRG (n.d.) A Partnership at Risk? The UN-NGO Relationship in Light of UN Integration, NRC Discussion Paper, Oslo: Norwegian Refugee Council

OECD (2011) 2011 Report on International Engagement in Fragile States - Somali Republic, Paris: Organisation for Economic Co-operation and Development (OECD) Publishing

Ruggie, John Gerard (1993) Multilateralism Matters: The Theory and Praxis of an Institutional Form, New Directions in World Politics, New York: Columbia University Press

Schmidt, Anna (2006) 'Social Networks', in Mark Bevir (ed.), Encyclopedia of Governance, Thousand Oaks CA: Sage Publications

Slaughter, A.-M. (2004) A New World Order: Government Networks and the Disaggregated State, Princeton: Princeton University Press
Tarp, Finn (ed.) (2000) Foreign Aid and Development - Lessons Learnt and Direction for the Future, London: Routledge

Thery, Alain and Amici, Andrea (2012) Evaluation of the UNDP Somali Institutional Development Programme, Brussels: European Union/ SOFRECO

United Nations Security Council (2011) Report of the Monitoring Group on Somalia and Eritrea Pursuant to Security Council Resolution 1916 (2010) $S / 2011 / 433$, New York

Von Hippel, Karin (2007) 'Blurring of Mandates in Somalia', in Larry Minear and Hazel Smith (eds), Humanitarian Diplomacy: Practitioners and their Craft, New York: United Nations University Press: 298-322

World Bank (1969) 'Partners in Development', Pearson Commision (1969), http://web.worldbank.org/WBSITE/EXTERNAL/ EXTABOUTUS/EXTARCHIVES/0,,content MDK:20121526 pagePK:36726 piPK:36092 $\sim$ theSitePK:29506,00.html (accessed 16 October 2012)

World Bank (2011) World Development Report 2011: Conflict, Security and Development, Washington DC: World Bank 